\title{
Effects of Depth of Needle Insertion with Risperidone Long-Acting Injectable in Persons with Schizophrenia: A Randomized Double-Blind Study
}

\author{
Yueren Zhao ${ }^{*}$, Tetsuya Tanioka², Yuko Yasuhara², Kensaku Takase ${ }^{3}$, Soji Tsuboi ${ }^{4}$, \\ Kiyoshi Fujita4, Rozzano C. Locsin², Nakao Iwata1 \\ ${ }^{1}$ Department of Neuropsychiatry, Fujita Health University School of Medicine, Aichi, Japan \\ ${ }^{2}$ Department of Nursing, Institute of Biomedical Sciences, Tokushima University Graduate School, Tokushima, Japan \\ ${ }^{3}$ Department of Rehabilitation, Tokushima Prefectural Central Hospital, Tokushima, Japan \\ ${ }^{4}$ Okehazama Hospital Fujita Kokoro Care Center, Aichi, Japan \\ Email: ^taipeeyen+OJP2017@gmail.com
}

How to cite this paper: Zhao, Y., Tanioka, T., Yasuhara, Y., Takase, K., Tsuboi, S., Fujita, K., Locsin, R.C. and Iwata, N. (2017) Effects of Depth of Needle Insertion with Risperidone Long-Acting Injectable in Persons with Schizophrenia: A Randomized Double-Blind Study. Open Journal of Psychiatry, 7, 374-385.

https://doi.org/10.4236/ojpsych.2017.74031

Received: September 1, 2017

Accepted: October 8, 2017

Published: October 11, 2017

Copyright (c) 2017 by authors and Scientific Research Publishing Inc. This work is licensed under the Creative Commons Attribution International License (CC BY 4.0).

http://creativecommons.org/licenses/by/4.0/

\section{(c) (i) Open Access}

\begin{abstract}
In some cases, if the insertion depth is shallower than expected, intramuscular (IM) injection of risperidone long-acting injectable (RLAI) may not penetrate the muscle fascia. However, if needle insertion depth is deeper than anticipated, needle penetration may cause damage to nerves, arteries and veins. Few clinical studies were done to evaluate the depth of needle length insertion reaching the intended gluteal muscle. The aim of this study was to evaluate the suitable depth of injecting RLAI. Twenty-six patients with schizophrenia were treated with RLAI, and randomly divided into two groups: $50 \mathrm{~mm}$ needle inserted group (Group-D, deep insertion, $\mathrm{n}=13$ ) and $20 \mathrm{~mm}$ needle insertion group (Group-S, shallow insertion, $n=13$ ). For Group-S, the needle length was marked with a spacer at exactly $20 \mathrm{~mm}$. Injections were performed by the psychiatrist or nurse, alternating between the two gluteal sites by double-cross method every two weeks. Clinical psychotic symptoms and injection site reactions were recorded throughout the study period. Experienced psychologists who were blinded from the needle-length experimental variable evaluated patients' psychotic symptoms using the Positive and Negative Syndrome Scale (PANSS) every two weeks. The plasma 9-hydroxyrisperidone (9-OH-RIS) concentrations were measured every two weeks; comparison data were determined on the 8th week and the 14th week. No significant difference was observed in 9-OH-RIS concentrations, psychotic symptoms, injection site skin reactions of subjects in both groups. However, in Group-D, injection site
\end{abstract}


adverse reactions were confirmed in two subjects (15\%). In Group-S, injection site reactions were confirmed in six subjects (46\%). Although effective 9-OH-RIS concentrations were obtained with the insertion using both depth, it was concluded that the $50 \mathrm{~mm}$ insertion length was more suitable for dorsogluteal IM injections in adult patients with schizophrenia as demonstrated by the incidence of local adverse skin reactions.

\section{Keywords}

Inserted Depth of Injection Needle, Long-Acting Injectable, Persons with Schizophrenia, Randomized Double-Blind Study, 9-Hydroxyrisperidone Pharmacokinetics

\section{Introduction}

Relapses prevention constitutes one of the primary treatment goals for the successful long-term management of schizophrenia [1] [2]. Similarly, poor medication adherence contributes to negative treatment response, symptom relapse, and frequent re-admissions of schizophrenic patients [3] [4]. Increasing medication adherence is critical to improving outcomes among these patients. A long-acting injectable (LAI) antipsychotic medication is one of the most effective methods for enhancing treatment adherence and decreasing re-hospitalization rates in patients with schizophrenia [5] [6] [7].

First- and second-generation antipsychotic LAI therapies may improve medication adherence compared to oral antipsychotics [8] [9]. Evidence has been established that LAI antipsychotics demonstrate distinct benefits in the multi-episode, non-adherent, "revolving door" patient [10]. In previous research, discussion focused on the LAI's kinetic properties, relationships between plasma concentrations with clinical effects, and conversion from oral to injectable therapy [11]. However, for the second-generation LAI, there were only few reports on the method to determine the suitability of injection sites of RLAI, which takes into consideration injection needle insertion depth, plasma 9-hydroxyrisperidone (9-OH-RIS) concentration, psychotic symptoms and injection site reactions.

In past research studies, concerning the injection method of LAI using ultrasonic examination [12] [13], it was determined that there were individual differences in the distance from the epidermis to the under-fascia (DEUF) of gluteus maximus muscle or gluteus medius muscle for each patient. Concerning the injection insertion depth in the case of IM injection, particularly in the case of LAI, a shallow insertion depth sometimes occurs and the needle does not penetrate the muscle fascia and as a result the medication is delivered into the subcutaneous tissue, or it happens that some of the medication leaks into the subcutaneous tissue. However, it was also found that when the insertion depth is deep, the needle insertion distance is widened, so that possible damage to blood vessels and nerves can happen. No method has been established to objectively evaluate 
the most appropriate method for RLAI administration.

\section{Purpose}

The aim of this study was to determine an appropriate injection needle penetration depth of RLAI by examining pharmacokinetic differences, psychotic symptoms, injection site reactions, and depth of needle insertion.

\section{Methods}

\subsection{Data Collection Methods}

\subsubsection{Measurement by Ultrasonography}

For all patients receiving RLAI, IM injection and ultrasonography were performed in advance following this procedure: Nurse Investigators who have used the "Double Cross" method to determine the gluteal muscle injection site performed the procedure thereby ensuring consistency in the insertion method. The "Double Cross" method divides the buttocks with an imaginary cross, and then divides the upper outer quadrant by another imaginary cross [14]. The DEUF, and distance from the epidermis to the iliac bone (DEI) at bilateral gluteal sites were assessed using a standardized ultrasonography [12]. Results of ultrasonographic measurements were done based on the recorded ultrasonographic images. All ultrasonographic measurements were performed by an experienced Sonographer using a 7.5 MHz linear and convex array transducer and real-time-B-mode ultrasonography diagnostic system (Hitachi Medical Corporation, Japan). Ultrasonographic images were made at the dorsogluteal injection site. DEUF and DEI measurements were made above and outside a line drawn from the posterior superior iliac spine to the greater trochanter of the femur. The ultrasonography probe was held at a right angle to the skin at the gluteal region.

\subsubsection{Measurement Items and Analysis Method}

Clinical psychotic symptoms and injection site reactions were recorded throughout the study period. Also, two experienced psychologists evaluated patients' psychotic symptoms using the Positive and Negative Syndrome Scale (PANSS) every two weeks. All evaluators and clinicians were not informed about subject belongs which group.

RLAI was administered by deep intramuscular injection at the gluteal site using the appropriate enclosed safety needle (2-inch needle for gluteal administration alternating injections between the two buttocks) intramuscularly every 2 weeks. The plasma 9-OH-RIS concentrations ( $\mathrm{ng} / \mathrm{ml}$ ) [15] [16] were measured seven times every two weeks from the start of this test. It was considered that substantial release of risperidone into plasma begins only at 2 to 3 weeks post injection, increasing during weeks 3 and 4 , and maintained during weeks 4 through 6 . With repeated injections every 2 weeks, steady-state levels are usually reached by weeks 6 to 8 [17] [18]. For this reason, 9-OH-RIS concentrations were compared at the fourth ( 8 weeks) and seventh visit (14 weeks) from the 
start of this study.

It was confirmed that there is no difference between age, body mass index (BMI), and dose of RLAI in both groups. The Wilcoxon signed rank test was used in comparing clinical symptoms determined by the total score of PANSS, the 9-OH-RIS concentrations, and aforementioned measurement items.

The injection site reactions (redness, swelling, and a palpable mass) were compared using Fisher's exact test and Chi square test between two groups. Statistical analyses of data were performed using PASW Statistics (Ver. 18.0J). $P$ value of $<0.05$ level was considered statistically significant.

\subsubsection{Study Period}

The study was conducted from December 2013 to May 2014.

\subsubsection{Spacer Device for the Injection Needle}

Needle-length insertion was also guided by the spacer device for the injection needle devised to accurately insert only $20 \mathrm{~mm}$ length of the needle (Figure 1). Plastic caps attached to unused RLAI-specialized needles collected through sanitary procedure were cut off. It was processed so that the needle could be inserted accurately to a depth of $20 \mathrm{~mm}$ from the tip of the needle. Autoclave sterilization was done and the needles and caps were discarded.

\subsection{Subjects and Study Location}

\subsubsection{Subjects}

There were twenty-six adult patients diagnosed with schizophrenia of whom 18 were men and 8 were women, those were already prescribed RLAI. These subjects were recruited from Okehazama Hospital Fujita Kokoro Care Center, Aichi, Japan.

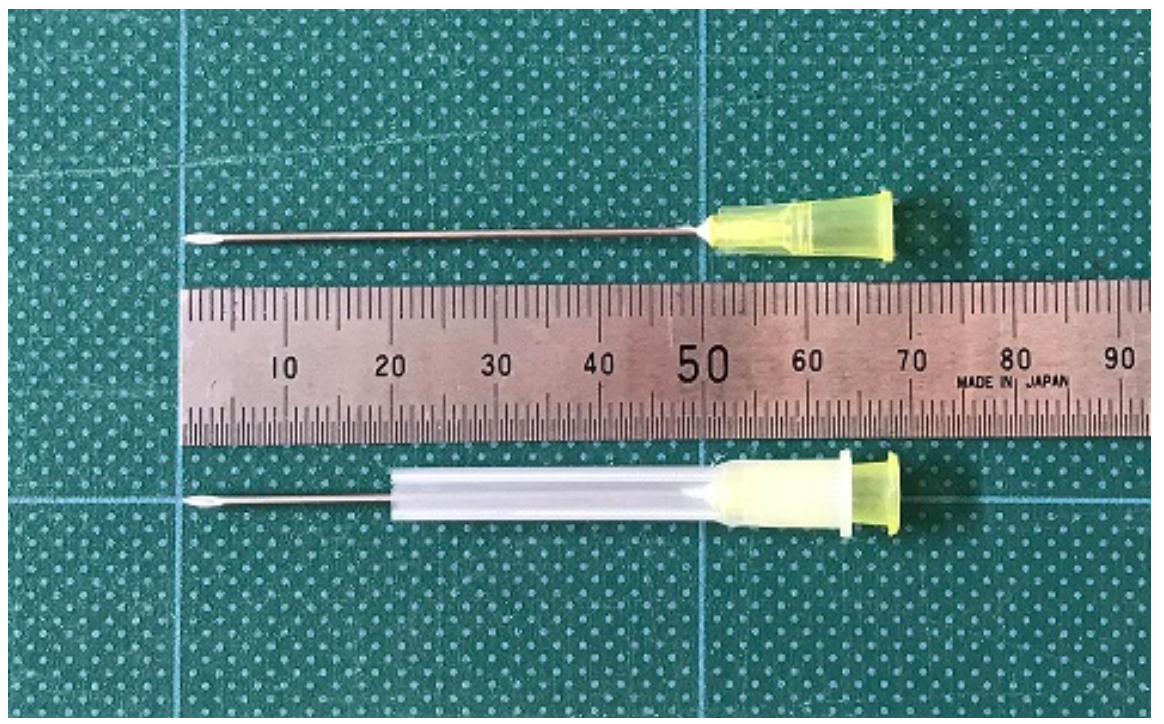

Figure 1. Injection needles use in this study. Upper: The RLAI-specialized 20 gauge injection needle, $50 \mathrm{~mm}$ ( 2 inches) in length. Lower: Injection needle with a spacer device, $20 \mathrm{~mm}$ in length from the tip of needle to the proximal end of the spacer device. 


\subsubsection{Inclusion and Exclusion Criteria}

The subjects were patients meeting all of the following inclusion criteria, namely: Out/In-patients, 20 years of age or older at the time the informed consent was obtained; Patients with schizophrenia who met the DSM-IV-TR diagnostic criteria; Patients who required treatment with RLAI, as well as all those who were being administered RLAI regularly for more than 8 weeks from the base line date of the study; and Patients who personally gave written informed consent to participate in the study. The exclusion criteria were: Patients with a prior history of hypersensitivity to risperidone; and those PANSS total score was equal to or higher than 130.

Meanwhile, the patients whose severity scores of Positive and Negative Syndrome Scale (PANSS) was less than 130 points participated in this research out of those whose total scores were between $30-210$ points. The participants were those patients who could maintain daily life activities at home or in the hospital environment, of single status or who received the support of care-givers such as family members despite having symptoms from mild to moderate based on the PANSS.

\subsubsection{Determination of Insertion Depth of Injection Needle}

Zaybak et al. [19] measured subcutaneous tissue thickness at the dorsogluteal area to determine optimal needle length for dorsogluteal IM injections in adults with BMI of more than $24.9 \mathrm{~kg} / \mathrm{m}^{2}$. They concluded that a needle longer than 1.5 inches should be used in women whose BMI is more than $24.9 \mathrm{~kg} / \mathrm{m}^{2}$, however, the dorsogluteal site may be used in patients who are overweight and in obese men. The ventrogluteal site may be used only among overweight men.

As generally observed among nurses practicing IM injection in the real world of clinical practice in Japan and based on the results of a questionnaire survey, IM injection is often performed using the ordinary injection needle with a length of $38 \mathrm{~mm}$, with the injection needle being inserted $1 / 2$ or $2 / 3$ of its length [20]. The length of the RLAI-specialized injection needle is $50 \mathrm{~mm}$. The designated injection needle on the buttocks for the second-generation anti-psychotic agent LAI (Paliperidone palmitate) is $38 \mathrm{~mm}$. Therefore, in this study, we set the insertion depth of Group-D to $50 \mathrm{~mm}$ which is the same as that of the RLAI-specialized $50 \mathrm{~mm}$ injection needle, and the one of Group-S to a length of $1 / 2$ or more of the $38 \mathrm{~mm}$ injection needle, that is, $20 \mathrm{~mm}$. Applying the Hochstetter and Clark's point measurement method on the injection sites reveals that the distance from epidermis to iliac bone (DEI) is short [21]. So, it was judged that the tip of the injection needle for RLAI might touch an iliac bone. In this study, therefore, the double cross method was applied for the method to determine the injection site. It was confirmed by ultrasonic examination that DEI from injection sites by double cross method was more than $50 \mathrm{~mm}$ in all subjects.

\subsection{Ethical Considerations}

This study was conducted after approval was received from the Okehazama Hospital Fujita Kokoro Care Center's Ethics Committee. Both verbal and written 
consents were obtained from the prospective subjects of the study. Patient consent for ultrasonography images was also obtained. The consent also included a statement of understanding that images may be used for educational purposes, lectures, and publications. A double blind trial without disclosure of assignment contents was conducted.

\section{Results}

Table 1 is a comparison result for confirming that both groups have the same conditions. It was confirmed that there was no significant difference in age, BMI, dose of RLAI in both groups.

Table 2 shows the parameters of the variables such as characteristics of injection site reaction, RLAI dose and risperidone plasma concentration from the start of the study to the seventh occasion of RLAI administration. During the study period, patients in Group-D showed injection site reactions in two subjects out of $13(15 \%)$. The injection site reactions were palpable and circumscribed masses beneath the subcutaneous tissue for both subjects. This palpable mass was found in a subject four times during the second, third, fourth and sixth data collection time. In Group-S patients, the injection site reactions were confirmed in six subjects out of 13 (46\%). The injection site reactions were palpable masses for four subjects and apparent swellings for two more patients. Palpable masses were observed twice in a subject at the fifth and seventh data collection time. However, there was no significant difference in the incidence rate of injection site reaction in both groups (Chi-square value $=1.55, p=0.21$ ).

There was no significant difference in the transition of risperidone plasma concentration and psychotic symptoms in both groups (Table 3 ).

\section{Discussion}

Risperidone is a second-generation antipsychotic agent commonly prescribed and used in the treatment of patients with schizophrenia. Despite its common use, there is limited documentation available on its pharmacokinetics in a naturalistic setting [22]. Only recently, a paper was published in which the 9-OH-RIS concentration of RLAI was measured and its relationship with injection needle

Table 1. Comparison results between Group-D and Group-S regarding patients age, BMI and dose of RLAI.

\begin{tabular}{ccccccccc}
\hline & \multicolumn{3}{c}{ Group-D $(\mathrm{N}=13)$} & \multicolumn{2}{c}{ Group-S (N=13) } & Z & $P$ \\
\cline { 2 - 5 } & Minimum & Median & Maximum & Minimum & Median & Maximum & & \\
\hline Age (years) & 22.00 & 58.00 & 74.00 & 37.00 & 56.00 & 69.00 & -0.59 & 0.55 \\
BMI & 21.70 & 23.80 & 32.10 & 22.10 & 27.10 & 36.20 & -1.07 & 0.29 \\
Dose of RLAI (mg) & 25.00 & 50.00 & 50.00 & 25.00 & 50.00 & 50.00 & -0.36 & 0.72
\end{tabular}

Wilcoxon Signed-rank Test. Group-D: $50 \mathrm{~mm}$ needle inserted group, Group-S: $20 \mathrm{~mm}$ needle inserted group. BMI: Body Mass Index, RLAI: risperidone long acting injectable. 
Table 2. Demographic and clinical characteristics of 26 patients.

\begin{tabular}{|c|c|c|c|c|c|c|c|c|}
\hline & Gender & $\begin{array}{c}\text { Age } \\
\text { (Years) }\end{array}$ & $\begin{array}{c}\text { BMI } \\
\left(\mathrm{kg} / \mathrm{m}^{2}\right)\end{array}$ & $\begin{array}{c}\text { Dose of } \\
\text { RLAI }(\mathrm{mg})\end{array}$ & $\begin{array}{l}\text { Pre-9-hydroxyrisperidone } \\
\text { (ng/ml) }\end{array}$ & $\begin{array}{l}\text { Post-9-hydroxyrisperidone } \\
\text { (ng/ml) }\end{array}$ & $\begin{array}{l}\text { Injection } \\
\text { site reactions }\end{array}$ & $\begin{array}{l}\text { Occurrence } \\
\text { time }\end{array}$ \\
\hline \multirow{13}{*}{$\begin{array}{l}\text { Group-D } \\
(\mathrm{N}=13)\end{array}$} & $\mathrm{F}$ & 56 & 21.7 & 25 & 13.6 & 9.78 & & \\
\hline & $\mathrm{F}$ & 22 & 21.8 & 37.5 & 13.2 & 11.6 & & \\
\hline & M & 70 & 22.7 & 25 & 25.1 & 47.3 & & \\
\hline & M & 46 & 22.8 & 50 & 16.7 & 20 & & \\
\hline & M & 57 & 23.2 & 50 & 6.93 & 8.33 & & \\
\hline & $\mathrm{F}$ & 74 & 23.3 & 50 & 25.1 & 15.6 & & \\
\hline & M & 69 & 23.8 & 50 & 27.6 & 14.4 & $\operatorname{mass}^{\text {a) }}$ & \\
\hline & M & 60 & 27 & 37.5 & 7.47 & 5.96 & mass & Fifth \\
\hline & M & 57 & 28.2 & 37.5 & 11.5 & 16.4 & & \\
\hline & F & 50 & 28.6 & 50 & 10.3 & 10.4 & & \\
\hline & M & 62 & 30 & 50 & 7.55 & 7.71 & & \\
\hline & $\mathrm{F}$ & 58 & 30.7 & 25 & 19.9 & 17.4 & & \\
\hline & M & 62 & 32.1 & 50 & 13.4 & 13.7 & & \\
\hline \multirow{13}{*}{$\begin{array}{l}\text { Group-S } \\
(\mathrm{N}=13)\end{array}$} & M & 56 & 22.1 & 50 & 11.2 & 12 & & \\
\hline & M & 56 & 22.7 & 50 & 10.4 & 11.6 & mass & Second \\
\hline & M & 37 & 23.3 & 50 & 8.93 & 9.53 & & \\
\hline & M & 40 & 24.2 & 25 & 11 & 7.31 & & \\
\hline & $\mathrm{F}$ & 59 & 24.5 & 37.5 & 8.8 & 8.38 & & \\
\hline & M & 52 & 25.5 & 50 & 67 & 69 & & \\
\hline & $\mathrm{F}$ & 42 & 27.1 & 50 & 35.6 & 36.7 & & \\
\hline & M & 68 & 28.9 & 50 & 31.3 & 24.8 & mass & Fourth \\
\hline & M & 53 & 29.3 & 50 & 20 & 22 & swelling & Second \\
\hline & M & 69 & 30.7 & 25 & 33.6 & 30.7 & swelling ${ }^{\mathrm{b})}$ & \\
\hline & M & 67 & 31.1 & 37.5 & 6.23 & 8.92 & mass & Seventh \\
\hline & $\mathrm{F}$ & 62 & 34.2 & 37.5 & 27.1 & 28.6 & & \\
\hline & M & 40 & 36.2 & 50 & 8.79 & 4.72 & mass & Fourth \\
\hline
\end{tabular}

Group-D: $50 \mathrm{~mm}$ needle inserted group, Group-S: $20 \mathrm{~mm}$ needle inserted group. $\mathrm{M}=$ male, $\mathrm{F}=$ female. During the test period, in Group-D, injection site reactions were confirmed in two patients out of 13 (15\%). In Group-S, injection site reactions were confirmed in six patients out of 13 (46\%). ${ }^{\text {a) }}$ The palpable mass was recognized in a patient four times at second, third, fourth and sixth time. ${ }^{\text {b) }}$ The injection site reactions were palpable masses for four patients and swellings for two. Palpable masses were observed twice in a patient at the fifth time and seventh time. There was no significant difference in the incidence rate of injection site reaction (Chi-square value $=1.55, p=0.21$ ). 9-hydroxyrisperidone plasma concentrations were compared at the fourth ( 8 weeks) and the seventh (14 weeks) from the start of this test. RLAI: risperidone long acting injectable. Pre: Measurement data at the fourth visit (8 weeks) from the start of this study. Post: Measurement data at the seventh visit (14 weeks) from the start of this study. 
Table 3. Pre- and post-injection 9-hydroxyrisperidone concentrations and psychiatric states in Group-D and Group-S.

\begin{tabular}{lcccccc}
\hline & & Minimum & Median & Maximum & $\mathrm{Z}$ & $P$ \\
\hline & Pre-9-OH-RIS (ng/ml) & 6.93 & 13.40 & 27.60 & -0.31 & 0.75 \\
Group-D & Post-9-OH-RIS (ng/ml) & 4.72 & 12.00 & 69.00 & & \\
$(\mathrm{~N}=13)$ & Pre-PANSS & 68.00 & 86.00 & 118.00 & & \\
& Post-PANSS & 67.00 & 83.00 & 113.00 & & \\
& Pre-9-OH-RIS (ng/ml) & 6.23 & 11.20 & 67.00 & & \\
& Post-9-OH-RIS (ng/ml) & 5.96 & 13.70 & 47.30 & & \\
Group-S & Pre-PANSS & 64.00 & 79.00 & 103.00 & & \\
$(\mathrm{~N}=13)$ & Post-PANSS & 70.00 & 76.00 & 102.00 & -0.35 & 0.73 \\
& & & & & & \\
& & &
\end{tabular}

Group-D: $50 \mathrm{~mm}$ needle inserted group, Group-S: $20 \mathrm{~mm}$ needle inserted group. Wilcoxon Signed-rank Test, PANSS: Positive and Negative Syndrome Scale, 9-hydroxyrisperidone (9-OH-RIS). Pre: Measurement data at the fourth visit (8 weeks) from the start of this study. Post: Measurement data at the seventh visit (14 weeks) from the start of this study.

insertion depth, psychotic symptoms and injection site reaction were discussed. However, there has been no study in which an ultrasonic determination was implemented before the examination and the relationship analyzed. Probably, that kind of research is the first-time study was conducted in the world. Nevertheless, in this research, measuring plasma 9-OH-RIS concentration and following up its effects using ultrasonic examination were found to be significant.

In this current study, the subjects were divided two groups by the needle insertion depth of $50 \mathrm{~mm}$ and of $20 \mathrm{~mm}$. There was no significant difference found in plasma 9-OH-RIS concentration, psychotic symptoms, injection site reaction and BMI in both groups.

RLAI is an aqueous suspension in which the active drug substance is encapsulated in a microsphere of polylactide-co-glycolide polymer. After injection, a small amount of risperidone $(<1 \%)$ is released by diffusion within 24 hours [23]. It was presumed that even if RLAI was injected into subcutaneous tissue, no significant difference would have been recognized in 9-OH-RIS concentration.

Previous research reported that there was no or minimal injection site pain and skin reactions were rare [24]. However, Quiroz et al. [25] reported that investigator-rated assessments of injection-site reactions were evident. The most common injection-site reaction was tenderness (RLAI gluteal injections-25 mg and $50 \mathrm{mg}$ : 10\% each; deltoid injections-37.5 mg: 18\%; $50 \mathrm{mg}$ : 19\%). Redness was observed in three percent of patients receiving $25 \mathrm{mg}$ and six percent of patients receiving $50 \mathrm{mg}$ of the RLAI gluteal muscle injections as well as in five percent of patients receiving $37.5 \mathrm{mg}$ and eight percent of patients receiving 50 $\mathrm{mg}$ of the RLAI deltoid muscle injections. There were few reports of swelling or indurations at either injection site. Injection-site reactions were most frequent at two and twelve hours post injection, and resolved thereafter, with almost no injection-site reactions reported beyond Day 3. 
In this current study, however, injection site reactions during the test period, of patients in Group-D were found to have injection site reactions (palpable mass in both subjects) confirmed in two subjects out of 13 (15\%). Patients in Group-D were observed to show subcutaneous swelling in four occasions. During the test period among patients in Group-S, their injection site reactions (palpable masses and swellings) were confirmed in six subjects out of 13 (46\%). Although there was no statistically significant difference in injection site reaction incidence, it was suggested that according to the incidence rate, inserting the injection needle deep into the muscle can possibly reduce the incidence of injection site reactions.

In most cases, injection-site reactions of two weeks post-injections were resolved thereafter. The case that had a palpable mass was observed to have the mass four times. The mass was considered a case-based incidence. In Group-D, insertion length site reactions were considered safe as compared with the patients' situation for those in Group-S.

The information that the injection needle should not be inserted up to its base came from cases wherein the needle came off and remained in the body when this injection needles were removed. This occurred during the times when injection needles were reusable [26]. However, recent disposable injection needles are improved so that even if an injection needle is inserted up to its base, there is no danger of the needle remaining in the body.

From a safety perspective, it is suggested that an optimal needle length for dorsogluteal IM injections in adults with BMI of more than $24.9 \mathrm{~kg} / \mathrm{m}^{2}$ is a needle longer than 1.5 inches [19] [27]. The length of the injection needle (22 gauge) for gluteal muscle injection designated for second-generation atypical antipsychotic LAI is $38 \mathrm{~mm}$, both in the case of paliperidone and of aripiprazole. In this study, it is also considered that it is preferable to insert the needle up to its base of about $38 \mathrm{~mm}$ for the aforementioned patients.

\subsection{Limitations}

The study has several limitations. One of these is the small sample size which may limit the generalization derived from the findings. Likewise, the researchers failed to equalize the numbers of people in the gender groups. It takes about 20 minutes per case to conduct IM injection while conducting an ultrasonic examination. It was difficult to conduct the latter while actual clinical work was being performed. However, if the ultrasonic examination could be carried out before all the IM injections, the reliability of the result would increase further.

Nevertheless, in the double-blind trial [28], consideration should be given to various reactions to patients occurring with a $20 \mathrm{~mm}$ IM injection needle in routine care settings.

\subsection{Implications for Future Research}

As a subject of future research, it would be advisable to confirm whether or not RLAI was in fact injected into the muscle using ultrasonic diagnostic equipment 
at the time of each injection. Moreover, if the relationship between the status of RLAI injection into the muscle and plasma concentration of risperidone can be investigated, then test results with further reliability can be obtained.

Performing a morphological investigation before LAI is injected is encouraged, as this type of investigation targeting buttock muscles using ultrasonic diagnostic equipment has become an inexpensive and convenient non-invasive diagnostic instrument. Since it is possible to examine not only buttock muscles but also the positional relationship among other tissues existing between skin and iliac bones and their anomalies such as arteriovenous anomalies, this morphological investigation is very useful not only to ensure the efficacy of the injection drug to be injected into the buttock muscles, but also for the reduction of risks posed by a needle's erroneous piercing of bone or of a blood vessel.

\section{Conclusions}

No significant difference was observed in the 9-OH-RIS concentration, psychotic symptoms, injection site reaction between the group of shallow insertion and that of deep insertion. However, in Group-D, injection site adverse reactions were confirmed in two subjects out of 13 (15\%). In Group-S, injection site reactions were confirmed in six subjects out of $13(46 \%)$.

Although effective 9-OH-RIS concentration can be obtained with the insertion of more than $20 \mathrm{~mm}$ needle insertion length, it was concluded that $50 \mathrm{~mm}$ insertion length is more suitable for dorsogluteal IM injections in adult patients with schizophrenia, from the view point of possible local skin adverse reactions.

\section{Acknowledgements}

The authors would like to thank the subject patients and all the staff members of the hospital who have helped us with this research. Especially, we also wish to thank Associate Professor Akihiro Hirakawa from Tokyo University for his advice on research planning; and we also sincerely thank Assistant Professor Toshiko Tanaka and Professor Reiji Yoshimura from University of Occupational and Environmental Health for their participation in this study and for helping us with risperidone plasma concentration analysis.

\section{References}

[1] Porcelli, S., Bianchini, O., De Girolamo D.G., Aguglia, E., Crea, L. and Serretti, A. (2016) Clinical Factors Related to Schizophrenia Relapse. International Journal of Psychiatry in Clinical Practice, 20, 54-69. https://doi.org/10.3109/13651501.2016.1149195

[2] Spaniel, F., Novak, T., Motlova, L., Capkova, J., Slovakova, A., Trancik, P., Matejka, M. and Höschl, C. (2015) Psychiatrist's Adherence: A New Factor in Relapse Prevention of Schizophrenia. A Randomized Controlled Study on Relapse Control through Telemedicine System. Journal of Psychiatric and Mental Health Nursing, 22, 811-820. https://doi.org/10.1111/jpm.12251

[3] MacEwan, J.P., Forma, F.M., Shafrin, J., Hatch, A., Lakdawalla, D.N. and Lindenmayer, J.P. (2016) Patterns of Adherence to Oral Atypical Antipsychotics among 
Patients Diagnosed with Schizophrenia. Journal of Managed Care \& Specialty Pharmacy, 22, 1349-1361. https://doi.org/10.18553/jmcp.2016.22.11.1349

[4] Tarutani, S., Kikuyama, H., Ohta, M., Kanazawa, T., Okamura, T. and Yoneda, H. (2016) Association between Medication Adherence and Duration of Outpatient Treatment in Patients with Schizophrenia. Psychiatry Investigation, 13, 413-419. https://doi.org/10.4306/pi.2016.13.4.413

[5] Wang, S.M., Han, C., Lee, S.J., Patkar, A.A., Masand, P.S. and Pae, C.U. (2014) Schizophrenia Relapse and the Clinical Usefulness of Once-Monthly Aripiprazole Depot Injection. Neuropsychiatric Disease and Treatment, 10, 1605-1611.

[6] Marcus, M.C., Zummo, J., Pettit, A.R., Stoddard, J. and Doshi, J.A. (2015) Antipsychotic Adherence and Rehospitalization in Schizophrenia Patients Receiving Oral Versus Long-Acting Injectable Antipsychotics Following Hospital Discharge. Journal of Managed Care \& Specialty Pharmacy, 21, 754-769.

https://doi.org/10.18553/jmcp.2015.21.9.754

[7] Piccinni, C., Piazza, A., Poluzzi, E., Tarricone, I., Koci, A., Berardi, D., Fioritti, A. and de Ponti, F. (2015) Social and Clinical Descriptors of Antipsychotic Prescription. The International Journal of Psychiatry in Medicine, 49, 45-62.

https://doi.org/10.2190/PM.49.1.d

[8] Nielsen, J., Jensen, S.O.W., Friis, R.B., Valentin, J.B. and Correll, C.U. (2015) Comparative Effectiveness of Risperidone Long-Acting Injectable vs First-Generation Antipsychotic Long-Acting Injectables in Schizophrenia: Results from a Nationwide, Retrospective Inception Cohort Study. Schizophrenia Bulletin, 41, 627-636. https://doi.org/10.1093/schbul/sbu128

[9] Pilon, D., Joshi, K., Tandon, N., Lafeuille, M., Kamstra, R.L., Emond, B. and Lefebvre, P. (2017) Treatment Patterns in Medicaid Patients with Schizophrenia Initiated on a First- or Second-Generation Long-Acting Injectable versus Oral Antipsychotic. Patient Preference and Adherence, 11, 619-629. https://doi.org/10.2147/PPA.S127623

[10] Agid, O., Foussias, G. and Remington, G. (2010) Long-Acting Injectable Antipsychotics in the Treatment of Schizophrenia: Their Role in Relapse Prevention. Expert Opinion on Pharmacotherapy, 11, 2301-2317. https://doi.org/10.1517/14656566.2010.499125

[11] Spanarello, S. and Ferla, T.L. (2014) The Pharmacokinetics of Long-Acting Antipsychotic Medications. Current Clinical Pharmacology, 9, 310-317. https://doi.org/10.2174/15748847113089990051

[12] Sakamaki, S., Yasuhara, Y., Motoki, K., Takase, K., Tanioka, T. and Locsin, R. (2013) The Relationship between Body Mass Index, Thickness of Subcutaneous Fat, and the Gluteus Muscle as the Intramuscular Injection Site. Health, 5, 1443-1448. https://doi.org/10.4236/health.2013.59196

[13] Masuda, S., Sakamaki, S., Yasuhara, Y., Zhao, Y., Takase, K., Kai, Y., Tanioka, T. and Locsin, R.C. (2016) Explanatory Variables as Evidence for Precision in Intramuscular Long-Acting Injections of Patients with Schizophrenia. Open Journal of Psychiatry, 6, 125-134. https://doi.org/10.4236/ojpsych.2016.61015

[14] Cocoman, A. and Murray, J. (2008) Intramuscular Injections: A Review of Best Practice for Mental Health Nurses. Journal of Psychiatric and Mental Health Nursing, 15, 424-434. https://doi.org/10.1111/j.1365-2850.2007.01236.x

[15] D’Souza, S., Faraj, J. and DeLuca, P. (2013) Microsphere Delivery of Risperidone as an Alternative to Combination Therapy. European Journal of Pharmaceutics and Biopharmaceutics, 85, 631-639. https://doi.org/10.1016/j.ejpb.2013.07.012 
[16] Ikai, S., Suzuki, T., Mimura, M. and Uchida, H. (2016) Plasma Levels and Estimated Dopamine $\mathrm{D}_{2}$ Receptor Occupancy of Long-Acting Injectable Risperidone during Maintenance Treatment of Schizophrenia: A 3-Year Follow-Up Study. Psychopharmacology, 233, 4003-4010. https://doi.org/10.1007/s00213-016-4428-1

[17] Rainer, M.K. (2008) Risperidone Long-Acting Injection: A Review of Its Long Term Safety and Efficacy. Neuropsychiatric Disease and Treatment, 4, 919-927. https://doi.org/10.2147/NDT.S3311

[18] Thyssen, A., Rusch, S., Herben, V., Quiroz, J. and Mannaert, E. (2010) Risperidone Long-Acting Injection: Pharmacokinetics Following Administration in Deltoid versus Gluteal Muscle in Schizophrenic Patients. The Journal of Clinical Pharmacology, 50, 1011-1021. https://doi.org/10.1177/0091270009355156

[19] Zaybak, A., Güneş, U.Y., Tamsel, S., Khorshid, L. and Eşer, I. (2007) Does Obesity Prevent the Needle from Reaching Muscle in Intramuscular Injections? Journal of Advanced Nursing, 58, 552-556. https://doi.org/10.1111/j.1365-2648.2007.04264.x

[20] Kikuchi, K., Takahashi, Y., Ishida, Y., Oyama, N., Takano, N., Murakami, S. and Kikuchi, K. (2007) Difficulty and Practical Knowledge of Intramuscular Injections by Nurses in Hospitals. Journal of the Faculty of Nursing, Iwate Prefectural University, 9, 53-63.

[21] Masuda, S., Yasuhara, Y., Tanioka T., Atsuta, A., Motoki, K., Takase, K. and Locsin, R.C. (2016) Comparison of Gluteal Muscle Intramuscular Injection Sites of Japanese Healthy Subjects: Considerations for Optimal Insertion of Injection Needle Length. Open Journal of Psychiatry, 6, 203-212. https://doi.org/10.4236/ojpsych.2016.62025

[22] Castberg, I. and Spigset, O. (2005) Serum Concentrations of Risperidone and 9-Hydroxyrisperidone after Administration of the Long-Acting Injectable Form of Risperidone: Evidence from a Routine Therapeutic Drug Monitoring Service. Therapeutic Drug Monitoring, 27, 103-106. https://doi.org/10.1097/00007691-200502000-00019

[23] Alphs, L., Gopal, S., Karcher, K., Kent, J., Sliwa, J.K., Kushner, S., Nuamah, I. and Singh, J. (2011) Are the Long-Acting Intramuscular Formulations of Risperidone or Paliperidone Palmitate Associated with Post-Injection Delirium/Sedation Syndrome? An Assessment of Safety Databases. Current Drug Safety, 6, 43-45. https://doi.org/10.2174/157488611794480070

[24] Lindenmayer, J.P., Jarboe, K., Bossie, C.A., Zhu, Y., Mehnert, A. and Lasser, R. (2005) Minimal Injection Site Pain and High Patient Satisfaction during Treatment With Long-Acting Risperidone. International Clinical Psychopharmacology, 20, 213-222. https://doi.org/10.1097/00004850-200507000-00004

[25] Quiroz, J.A., Rusch, S., Thyssen, A., Palumbo, J.M. and Kushner, S. (2011) Deltoid Injections of Risperidone Long-Acting Injectable in Patients with Schizophrenia. Innovations in Clinical Neuroscience, 8, 20-28.

[26] Fukuda, K., Ed. (1968) Kango no Kiso (Foundation of Nursing). Bunkodo Co. LTD, Tokyo. (In Japanese)

[27] Tanioka, T., Sakamaki, S., Yasuhara, Y., Tomotake, M., Takase, K., Watari, C., Makiguchi, K., Locsin, R., Motoki, K. and Inui, T. (2013) Optimal Needle Insertion Length for Intramuscular Injection of Risperidone Long-Acting Injectable (RLAI). Health, 5, 1939-1945. https://doi.org/10.4236/health.2013.512262

[28] Bobo, W.V. and Shelton, R.C. (2010) Risperidone Long-Acting Injectable (Risperdal Consta $^{\circledast}$ ) for Maintenance Treatment in Patients with Bipolar Disorder. Expert Review of Neurotherapeutics, 10, 1637-1658. https://doi.org/10.1586/ern.10.143 